\title{
THE PASSAGE OF GAS THROUGH THE WALLS OF PYROM- ETER PROTECTION TUBES AT HIGH TEMPERATURE
}

\author{
By Wm. F. Roeser
}

\section{ABSTRACT}

After a brief discussion of the contamination of thermocouples resulting from the use of tubes which are not gas tight, the results of the measurements of the rate of passage of air through 36 tubes of refractory porcelain (11 different classes), 2 of fused silica, 1 of pyrex glass, 2 of alundum, and 15 of metal are given for various temperatures which the tubes would withstand without noticeable deformation. Methods of testing are described and a very breif discussion given of the processes by which air may pass through the tube walls. The results also indicate the degree of vacuum obtainable in porcelain tubes at $1,400^{\circ} \mathrm{C}$.

\section{CONTENTS}

I. Introduction

Page

II. Apparatus and methods 485

III. Results

IV. Discussion of results 486

V. Summary

488

IV. Bibliography

494

494

\section{INTRODUCTION}

The wires of platinum to platinum rhodium thermocouples, as received from the manufacturers, are among the purest materials used in industrial plants and technical laboratories at the present time. Since the electromotive force generated by a thermocouple is very sensitive to changes in composition of its elements, the protection of the wires from contaminating gases and vapors is of prime importance. Base metal couples are usually protected by metal tubes and rare metal couples by tubes made of refractory porcelain or fused silica. In some cases, however, rare metal couples are portected by both porcelain and metal tubes.

In general, exposure to a reducing atmosphere is the most severe condition which is encountered. Little difficulty is encountered when thermocouples are used only in oxidizing or neutral atmospheres. Any reducing gas within the protection tube of a raremetal couple will generally produce contamination, particularly since the tube or insulators usually contain silica. The silica is reduced to silicon which is readily absorbed by platinum and its alloys. This not only changes the thermoelectric properties of the couples, but also impairs their mechanical properties.

At least one of the elements of a base-metal couple is usually an alloy and if the couple is exposed alternately to oxidizing and reducing atmospheres its thermoelectric properties are subject to great changes due to preferential oxidation and reduction of the components of the alloy wires, in addition to the contamination by 
silicon from the insulators. Gas-tight pyrometer protection tubes are, therefore, desirable in order to prevent any reducing gas from getting inside the protection tube. The most direct method of testing the effectiveness of tubes might be to observe changes in couples protected by various tubes exposed to reducing atmospheres under controlled conditions. This procedure would be tedious and expensive. Another method is to test the tubes for gas tightness when exposed to controlled reducing atmospheres. Since safe equipment was not available for making these tests, it was decided to test the tubes for gas tightness in air and, if possible, correlate the results with the very meager data vailable on the changes in the properties of couples when placed in the same type of tubes and exposed to reducing atmospheres. It may be taken as a general rule, having but few exceptions, that the air tightness of a tube is a good indication of its tightness with respect to deleterious furnace gases. This would certainly be true for leakage through cracks, pores, and small openings generally. Probably it would not be true for any process of transfer involving solution or chemical reaction which might take place.

There are very few data available on the rate of flow of air through the refractory materials widely used at high temperatures. One of these materials is the highly refractory procelain which is sometimes called sillimanite or mullite. The nickel-chromium alloys which probably corrode less than any of the other base metal alloys at high temperatures form another class of materials on which very few data are available.

An investigation was undertaken at the National Bureau of Standards to determine the rate of flow of air through the walls of various pyrometer protection tubes at high temperatures. The method used to determine air leakage through the various types of tubes furnishes, in addition, an indication of the degree of vacuum obtainable in them at high temperatures by the use of ordinary laboratory types of mercury vapor pumps. Several other materials similar in composition and characteristics to those previously mentioned have been included in this investigation. Most of the tubes were supplied by the leading manufacturers of pyrometers and pyrometer protection tubes. Their cooperation and interest in this project is greatly appreciated.

\section{APPARATUS AND METHODS}

The method of test consists in evacuating the tubes and measuring the rates of rise in pressure after the pump is shut off. A diagram of the apparatus is shown in Figure 1. The tubes being tested were placed in a horizontal cylindrical furnace and sealed to the pyrex glass vacuum system with De Khotinsky cement. The vacuum system consisted of a McLeod gage, a reservoir having a capacity of $2,320 \mathrm{~cm}^{3}$, and a mercury cutoff for sealing the system from the mercury vapor pump. The total volume of the system, depending somewhat upon the size of the tube being tested, was approximately $2,500 \mathrm{cc}$. The tubes were immersed in the furnace to a depth of $35 \mathrm{~cm}$.

A furnace wound with an alloy ribbon of 80 per cent platinum, 20 per cent rhodium was used in heating the porcelain and silica tubes. A platinum to platinum rhodium thermocouple placed with 


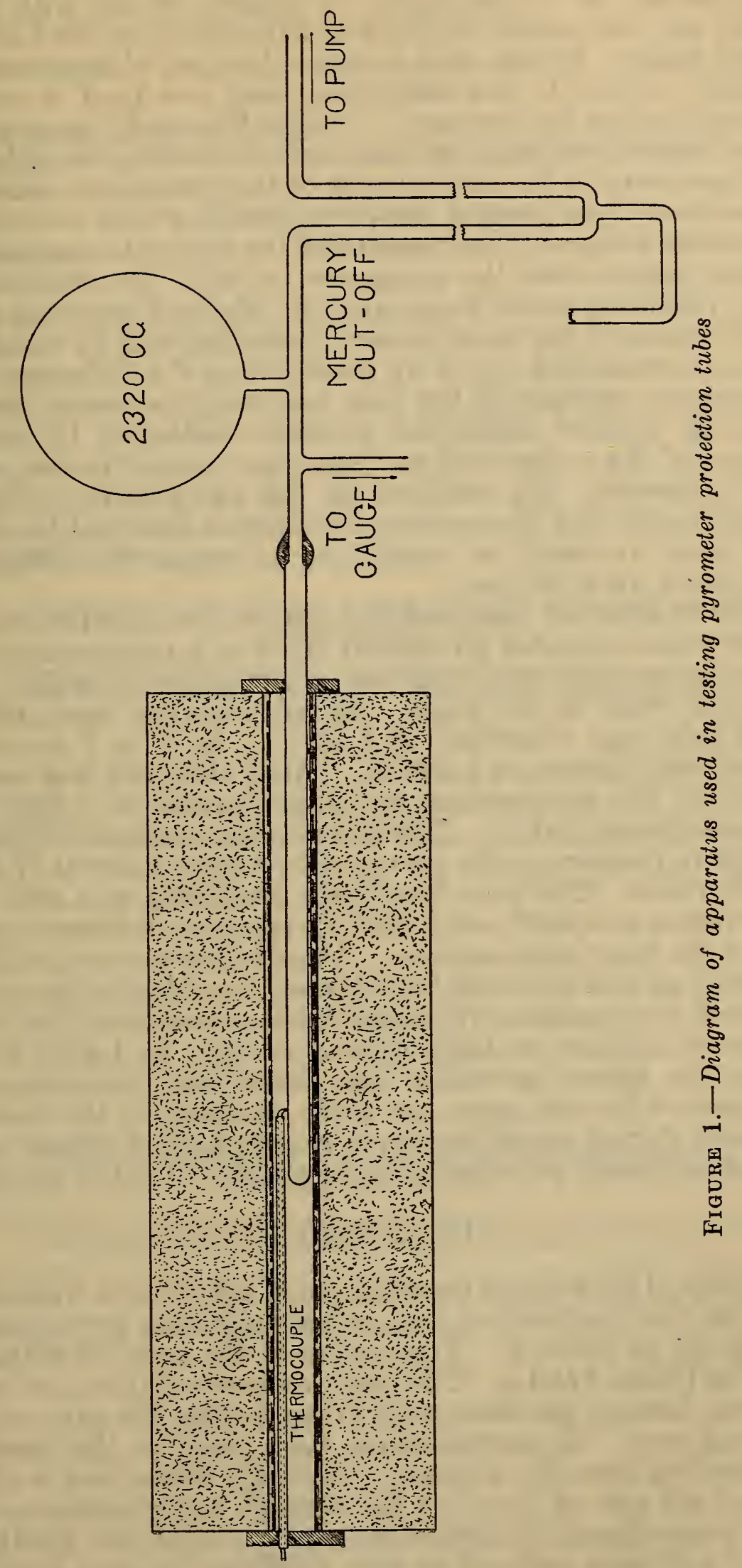


its junction near the center of the furnace was used in measuring and controlling the temperature. A furnace wound with an alloy wire of 80 per cent nickel, 20 per cent chromium was used in heating the metal tubes. In this case a chromel-alumel thermocouple with its junction welded to the tube under test was used in measuring and controlling the temperature. The De Khotinsky joint was water cooled to prevent softening by heat conducted along the tube. This was not necessary in the case of most of the porcelain or silica tubes.

The amount of air passing through a tube per hour was computed from the total volume of the system and the change in pressure during the known period when the pump was cut off. No provisions were made for removing water vapor and the McLeod gage was so operated as to measure the total pressure including that of water vapor. This was accomplished either by maintaining the difference in level of the mercury columns of the gage less than the vapor pressure of water at the time of taking the pressure reading or by measuring the volume of the compressed air (gases and vapor) in the gage at a series of pressures. No analyses of the gas passing through the tubes were made, but the pressure readings at different levels in the McLeod gage revealed no condensing of vapor for differences in mercury levels up to $60 \mathrm{~mm}$.

In order to drive off the gases and vapors from the inner surfaces, the tubes were evacuated for several hours at a temperature at least $100^{\circ} \mathrm{C}$. higher than the maximum temperature at which leakage observations were to be made. As an example, each refractory porcelain tube was evacuated at $1,400^{\circ} \mathrm{C}$. for 2 to 3 hours before taking the observations at $1,300^{\circ} \mathrm{C}$. After this tube was evacuated at $1,300^{\circ} \mathrm{C}$., the temperature was then lowered to $1,200^{\circ} \mathrm{C}$. and another observation taken. The observation consisted of measuring the change in pressure in the system over a time interval of approximately 16 hours. The tube was again evacuated at $1,400^{\circ} \mathrm{C}$. and the observation at $1,300^{\circ}$ and $1,200^{\circ} \mathrm{C}$. repeated, followed by observations at the lower temperatures. Usually the two sets of observations agreed as well as could be expected, considering the nature of the test and the possibility of changes in the structureof the material on continued heating at temperatures as high as $1,400^{\circ} \mathrm{C}$. In a few cases the above procedure was performed three times. The values reported in this paper are those obtained in the final set of observations during which the error caused by the release of gases and vapors originally adsorbed by the walls should not be appreciable.

\section{RESULTS}

The results of the tests on porcelain tubes are given in Tables 1,2, 3, and 4. The results of tests on opaque fused silica and pyrex glass tubes are also given in Table 4. The results of the tests on metal tubes are given in Tables 5 and 6 . The mean wall area of that portion of the tube in the furnace has been used in computing the rate of flow of gas per unit area. No correction has been made for that part of the tube protruding from the furnace. Although it has been well established that the rate of flow of a gas through a homogeneous solid is inversely proportional to the thickness of the solid, the results given here have not been reduced to unit thickness because there is no assurance that this would be justified in the case of such nonhomo- 
geneous specimens as glazed porcelain or plated metal tubes. The thickness of each tube is given in the tables.

TABLE 1.-Passage of air through American-made refractory porcelain tubes (unglazed), manufacturer $A$

[A mount of air passing through wall, expressed in units of $10^{-6} \mathrm{~cm}^{3} / \mathrm{hr}^{-} \cdot \mathrm{cm}^{2}$ reduced to room temperature and standard atmospheric pressure. Pressure difference one atmosphere]

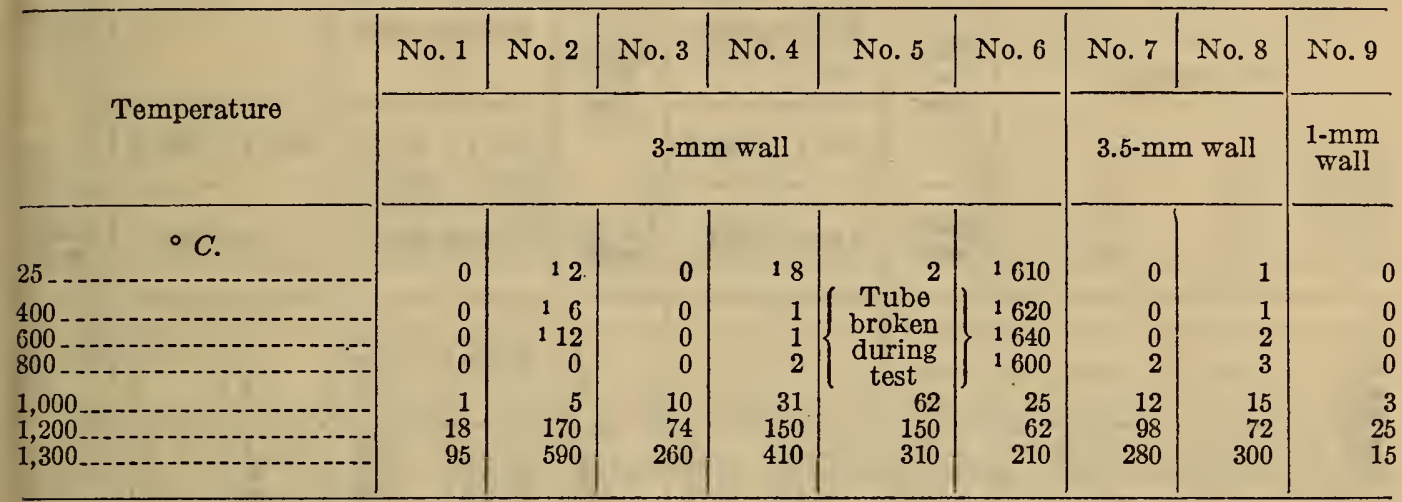

1 Tube cracked while cooling down.

TABLE 2.-Passage of air through American-made refractory porcelain tubes, manufacturer $B$

[A mount of air passing through wall, expressed in units of $10^{-6} \mathrm{~cm}^{3} / \mathrm{hr}$.- $\mathrm{cm}^{2}$ reduced to room temperature and standard atmospheric pressure. Pressure difference one atmosphere]

\begin{tabular}{|c|c|c|c|c|c|c|c|c|c|}
\hline \multirow{3}{*}{ Temperature } & \multicolumn{4}{|c|}{ Unglazed tubes } & \multicolumn{5}{|c|}{ Glazed tubes } \\
\hline & No. 1 & No. 2 & No. 3 & No. 4 & No. 1 & No. 2 & No. 3 & No. 4 & No. 5 \\
\hline & \multicolumn{2}{|c|}{ 3-mm wall } & \multicolumn{2}{|c|}{ 2-mm wall } & \multicolumn{2}{|c|}{ 3-mm wall } & \multicolumn{2}{|c|}{ 2-mm wall } & $\underset{\text { wall }}{1-\mathrm{mm}}$ \\
\hline $\begin{array}{c}{ }^{\circ} \mathrm{C} . \\
400 \\
400 \\
800- \\
1,000 \\
1,200 \\
1,300\end{array}$ & $\begin{array}{r}0 \\
0 \\
0 \\
5 \\
35 \\
110 \\
180\end{array}$ & $\begin{array}{r}0 \\
0 \\
0 \\
0 \\
1 \\
27 \\
49\end{array}$ & $\begin{array}{r}0 \\
0 \\
0 \\
0 \\
20 \\
150 \\
410\end{array}$ & $\begin{array}{r}2 \\
4 \\
8 \\
19 \\
46 \\
330 \\
740\end{array}$ & $\begin{array}{r}0 \\
0 \\
0 \\
4 \\
21 \\
83 \\
290\end{array}$ & $\begin{array}{r}2 \\
2 \\
2 \\
2 \\
5 \\
38 \\
210\end{array}$ & $\begin{array}{r}0 \\
0 \\
0 \\
0 \\
3 \\
61 \\
320\end{array}$ & $\begin{array}{r}0 \\
0 \\
0 \\
2 \\
21 \\
66 \\
150\end{array}$ & $\begin{array}{r}0 \\
0 \\
0 \\
0 \\
0 \\
7 \\
26\end{array}$ \\
\hline
\end{tabular}

TABLE 3.-Passage of air through American-made refractory porcelain tubes (unglazed), manufacturer $C$

[A mount of air passing through wall, expressed in units of $10^{-6} \mathrm{~cm}^{3} / \mathrm{hr}$.-cm $\mathrm{cm}^{2}$ reduced to room temperature and standard atmospheric pressure $\theta^{\circ}$ Pressure difference one atmosphere]

\begin{tabular}{|c|c|c|c|c|c|c|c|c|}
\hline \multirow{2}{*}{ Temperature } & No. 1 & No. 2 & No. 3 & No. 4 & No. 5 & No. 1 & No. 2 & \multirow{2}{*}{$\frac{\text { No. } 3}{\begin{array}{c}\text { 1-mm } \\
\text { wall }\end{array}}$} \\
\hline & \multicolumn{5}{|c|}{ 3-mm wall } & \multicolumn{2}{|c|}{2.5 -mm wall } & \\
\hline $\begin{array}{l}{ }^{\circ} \mathrm{C} . \\
400 \\
600 \\
800 \\
1,000 \\
1,200 \\
1,300\end{array}$ & $\begin{array}{r}150,000 \\
76,000 \\
58,000 \\
53,000 \\
53,000 \\
53,000 \\
53,000\end{array}$ & $\begin{array}{r}0 \\
0 \\
4 \\
25 \\
41 \\
190 \\
720\end{array}$ & $\begin{array}{r}0 \\
0 \\
1 \\
8 \\
55 \\
230 \\
330\end{array}$ & $\begin{array}{r}3 \\
3 \\
2 \\
9 \\
25 \\
310 \\
1,100\end{array}$ & $\begin{array}{r}0 \\
0 \\
0 \\
2 \\
19 \\
200 \\
820\end{array}$ & $\begin{array}{c}18 \\
(1) \\
(1) \\
11 \\
170 \\
570 \\
1,000\end{array}$ & $\begin{array}{r}0 \\
0 \\
0 \\
0 \\
10 \\
47 \\
380\end{array}$ & $\begin{array}{r}0 \\
0 \\
0 \\
0 \\
5 \\
24 \\
420\end{array}$ \\
\hline
\end{tabular}

1 Tube cracked while cooling down. 


\section{TABLE 4.-Passage of air through miscellaneous tubes}

[Amount of air passing through wall, expressed in units of $10^{-8} \mathrm{~cm}^{3} / \mathrm{hr}^{-}-\mathrm{cm}^{2}$ reduced to room temperature and standard atmospheric pressure. Pressure difference one atmosphere]

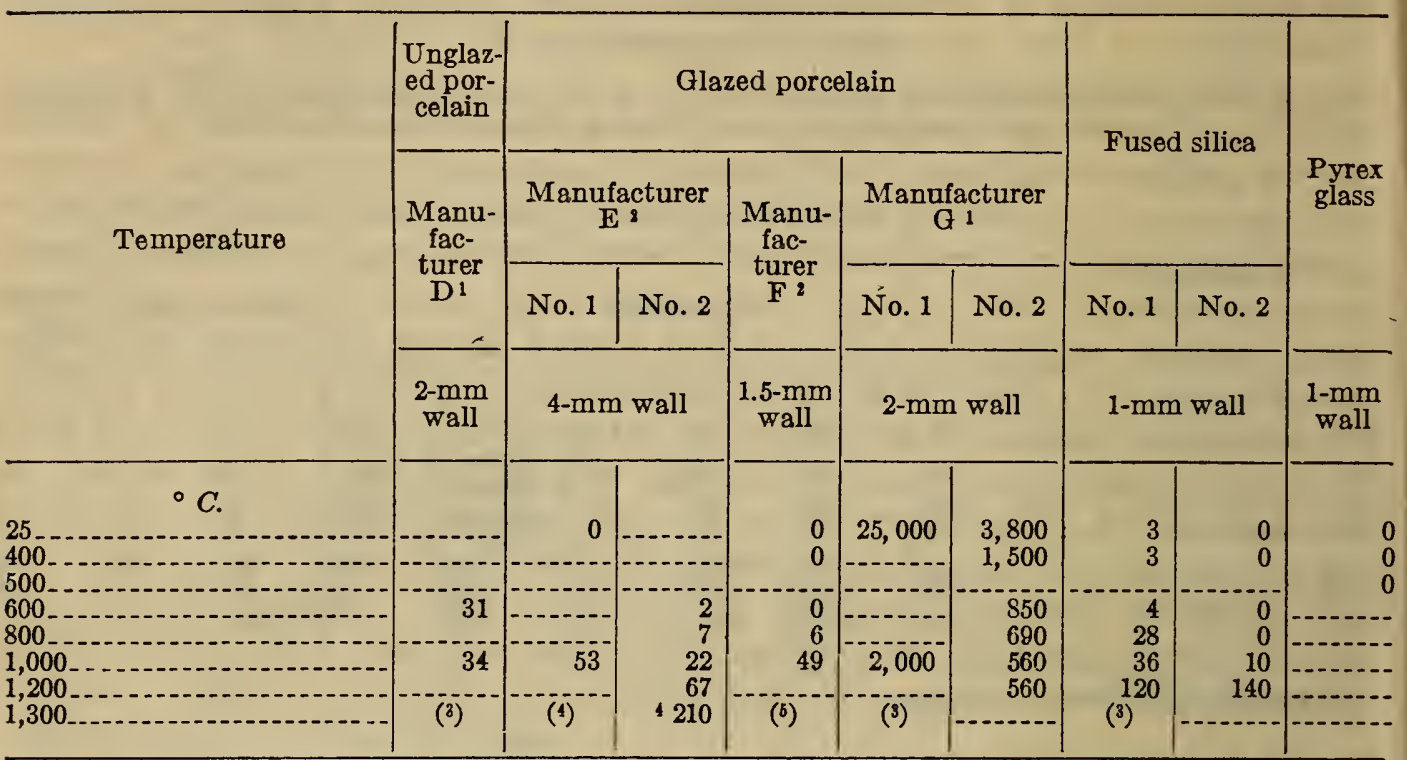

1 These tubes are not being manufactured at present.

2 These tubes were manufactured in Germany. The tube headed by manufacturer $\mathrm{F}$ was purchased previous to 1914.

3 Tubes collapsed at $1,400^{\circ} \mathrm{C}$.

1 Glaze stuck to furnace wall and opened holes in tubes.

${ }^{6}$ Soft glaze.

All of the following tubes leaked too rapidly for measurement in the vacuum system. The leakage was observed by subjecting the tubes to air pressure and immersing them in water.

1. Two unglazed porcelain tubes with 1-mm walls and one glazed porcelain tube with a $3-\mathrm{mm}$ wall obtained from manufacturer $\mathrm{D}$. Incidentally these tubes are no longer being manufactured.

2. Two unglazed tubes with $3-\mathrm{mm}$ walls obtained from an American, manufacturer $\mathrm{H}$.

3 . Two alundum tubes with $2.5-\mathrm{mm}$ walls.

TABLE 5.-Passage of air through nickel-chromium tubes (cast)

[A mount of air passing through wall, expressed in units of $10^{-6} \mathrm{~cm}^{3} / \mathrm{hr}^{-}-\mathrm{cm}^{2}$ reduced to room temperature and standard atmospheric pressure. Pressure difference one atmosphere]

\begin{tabular}{|c|c|c|c|c|c|c|}
\hline \multirow{3}{*}{ Temperature } & \multicolumn{3}{|c|}{ Manufacturer $\mathrm{J}$} & \multicolumn{3}{|c|}{ Manufacturer $\mathrm{K}$} \\
\hline & No. 1 & No. 2 & No. 3 & No. 1 & No. 2 & No. 3 \\
\hline & $\begin{array}{c}\text { 5-mm } \\
\text { wall }\end{array}$ & $\begin{array}{c}\text { 4-mm } \\
\text { wall }\end{array}$ & $\underset{\text { wall }}{\text { 5-mm }}$ & \multicolumn{3}{|c|}{ 6-mm wall } \\
\hline $\begin{array}{c}{ }^{\circ} C . \\
60000 \\
800 \\
1,000\end{array}$ & $\begin{array}{l}1,200 \\
1,200 \\
1,200 \\
1,400 \\
6,300\end{array}$ & $\begin{array}{r}1 \\
37 \\
62 \\
330 \\
3,300\end{array}$ & $\begin{array}{r}1 \\
30 \\
110 \\
330 \\
1,700\end{array}$ & $\begin{array}{r}170 \\
1,500\end{array}$ & $\begin{array}{r}1 \\
11 \\
45 \\
110 \\
770\end{array}$ & $\begin{array}{r}1 \\
15 \\
30 \\
67 \\
6,000\end{array}$ \\
\hline
\end{tabular}

Note.-Samples of these tubes collapsed at $1,200^{\circ} \mathrm{C}$. 
TABLE 6.-Passage of air through miscellaneous metal tubes

[Amount of air passing through wall, expressed in units of $10^{-6} \mathrm{~cm}^{3} / \mathrm{hr} .-\mathrm{cm}^{2}$ reduced to room temperature and standard atmospheric pressure. Pressure difference, 1 atmosphere]

\begin{tabular}{|c|c|c|c|c|c|c|c|c|c|}
\hline Temperature $\left({ }^{\circ} \mathrm{C}.\right)$ & $\begin{array}{l}\text { Ni-Mn } \\
\text { (cast), } \\
\text { 6-mm } \\
\text { wall }\end{array}$ & $\begin{array}{l}\mathrm{Ni}-\mathrm{Fe} \\
\text { (cast), } \\
4.5 \text {-mm } \\
\text { wall }\end{array}$ & $\begin{array}{c}\text { Cr-Fe } \\
\text { (drilled } \\
\text { from } \\
\text { solid } \\
\text { stock), } \\
\text { 6-mm } \\
\text { wall }\end{array}$ & $\begin{array}{l}\text { Cr-Fe } \\
\text { (rolled } \\
\text { and } \\
\text { weld- } \\
\text { ed), } \\
\text { 2-mm } \\
\text { wall }\end{array}$ & $\begin{array}{c}\text { Cr- } \\
\text { Steel } \\
\text { (drilled } \\
\text { from } \\
\text { solid } \\
\text { stock), } \\
\text { 5-mm } \\
\text { wall }\end{array}$ & $\begin{array}{c}\text { Extra } \\
\text { heavy } \\
\text { seamless } \\
\text { steel, } \\
\text { 6-mm } \\
\text { wall }\end{array}$ & $\begin{array}{l}\text { Cr- } \\
\text { plated } \\
\text { seam- } \\
\text { less } \\
\text { steel, } \\
\text { 3-mm } \\
\text { wall }\end{array}$ & $\begin{array}{c}\text { Calor- } \\
\text { ized } \\
\text { wrought } \\
\text { iron, } \\
3.5-\mathrm{mm} \\
\text { wall }\end{array}$ & $\begin{array}{l}\text { Ni-Cr }{ }^{1} \\
\text { welded } \\
\text { to iron, } \\
\text { 5-mm } \\
\text { wall }\end{array}$ \\
\hline $\begin{array}{l}400 \\
6000 \\
1,000\end{array}$ & $\begin{array}{r}110,000 \\
55,000 \\
37,000 \\
33,000 \\
55,000\end{array}$ & $\begin{array}{r}13,000 \\
12,000 \\
10,000 \\
9,100 \\
12,000\end{array}$ & $\begin{array}{r}3 \\
36 \\
750 \\
3,600 \\
58,000\end{array}$ & $\begin{array}{r}5,500 \\
1,800 \\
1,700 \\
2,500 \\
21,000\end{array}$ & $\begin{array}{r}4 \\
9 \\
37 \\
99 \\
3,700\end{array}$ & $\begin{array}{r}2,000 \\
2,400 \\
3,200 \\
54,000 \\
760,000\end{array}$ & $\begin{array}{r}12 \\
37 \\
490 \\
11,000 \\
37,000\end{array}$ & $\begin{array}{r}8 \\
11 \\
52 \\
130 \\
210\end{array}$ & $\begin{array}{l}230,000 \\
170,000 \\
150,000 \\
130,000 \\
180,000\end{array}$ \\
\hline
\end{tabular}

1 This tube leaked through pinholes in the Ni-Cr. Another tube was tested, but leaked through pinhole in the weld.

Measurements show that if the pressure of the system was 0.001 $\mathrm{mm}$ of $\mathrm{Hg}$ with the pump operating steadily then the leakage of gas into the system was approximately $0.12 \mathrm{~cm}^{3} / \mathrm{hr}$. (reduced to room temperature and atmospheric pressure). Since the mean area of a tube in the furnace was approximately $150 \mathrm{~cm}^{2}$, this corresponds to a leak of about $800 \times 10^{-6} \mathrm{~cm}^{3} / \mathrm{hr}$.- $\mathrm{cm}^{2}$. The pressure in the system with the pump operating was less than $0.001 \mathrm{~mm}$ of $\mathrm{Hg}$ for most of the refractory porcelain tubes at $1,300^{\circ} \mathrm{C}$.

For those tubes which leaked less than $400 \times 10^{-6} \mathrm{~cm}^{3} / \mathrm{hr} .-\mathrm{cm}^{2}$ at $1,300^{\circ}$ C., the pressure in the system with the pump operating steadily and the tube at $1,400^{\circ} \mathrm{C}$. was usually less than $0.001 \mathrm{~mm}$ of $\mathrm{Hg}$. A few measurements made on some of the tubes indicated that the leak was approximately twice as much at $1,400^{\circ}$ as at $1,300^{\circ} \mathrm{C}$.

\section{DISCUSSION OF RESULTS}

A study of the data reveals that tubes which leak less than $500 \times 10^{-6}$ $\mathrm{cm}^{3} / \mathrm{hr}^{-}-\mathrm{cm}^{2}$ at $1,300^{\circ} \mathrm{C}$. for a pressure difference of 1 atmosphere, may be obtained from several sources. Experience with such tubes in a reducing atmosphere indicates that they are sufficiently gas tight for use as primary pyrometer protection tubes. Experience also indicates that the use of tubes which leak badly may result in contamination of thermocouples, especially under adverse conditions. In the absence of a contaminating atmosphere, gas tightness may be of little importance. It seems reasonable to require tubes which do not leak more than about $500 \times 10^{-6} \mathrm{~cm}^{3} / \mathrm{hr}$. $-\mathrm{cm}^{2}$ at $1,300^{\circ} \mathrm{C}$. since, in general, the American-made refractory porcelain tubes which were gas tight at room temperature meet this requirement.

Research workers desiring to maintain an evacuated space at high temperatures may be guided in their requirements by the degree of vacuum desired and by the limitations of the materials as indicated by measurements. As the tubes tested in this investigation were presumably not selected, it is entirely possible that better performance would be obtained with selected tubes.

Theoretical analysis of the passage of air through solids at high temperatures is extremely difficult because of our lack of knowledge of the structure of solids. The structure of porcelain is indeed complex and indefinite. In general, porcelain may be regarded as a translucent body composed essentially of mullite $\left(3 \mathrm{Al}_{2} \mathrm{O}_{3} \cdot 2 \mathrm{SiO}_{2}\right)$ 
crystals in a glass matrix and often containing undissolved quartz and clay. Little is known regarding the properties of the glass matrix. The relative amounts of mullite, glass, quartz, and clay will depend upon a great many factors, such as the composition of raw materials, amount and kind of flux used, firing temperature, etc.

The physical processes by which air may pass through such solids may be divided into three general classes, namely, (1) viscous flow through pinholes (holes which are large in diameter compared to the mean free path of the gas molecules), (2) molecular flow through very fine capillaries or interstices, and (3) diffusion of dissolved gases through the solid.

If a tube leaks through one or more pinholes (defined as above), the volume of gas flowing through the holes, according to the kinetic theory is inversely proportional to the viscosity (assuming constant dimensions of the holes). Since the viscosity of a gas increases with temperature, the flow through such holes should decrease as the temperature increases. Some of the tubes studied in this investigation leaked through pinholes, and it was found in some cases that the quantity of gas leaking into the tubes decreased as the temperature increased up to some point (approximately $800^{\circ}$ C.) at which other factors began to play an important part. Calculations show that the mass (or volume reduced to standard conditions) of gas flowing through pinholes should be approximately five times as much at room temperature as at $500^{\circ} \mathrm{C}$. However, if the tube has several pinholes in it and some of these holes are in that part of the tube protruding from the furnace, the relation between the leakage and temperature becomes more complicated. Tubes which leak in this way are of no particular interest in this investigation, since such large leaks can be found easily and the tubes discarded.

Tubes may be tested for large pinholes by applying air pressure to the tubes and immersing them in water. The presence of pinholes is indicated by bubbles. It is very important that the air pressure be applied to the tubes before immersion. Tubes on which bubbles formed when tested in this way failed to yield bubbles when immersed before the application of the air pressure. The pressure used with these tubes was evidently not sufficient to force the adsorbed water from the holes or pores. Leaks as small as $10 \mathrm{~cm}^{3} / \mathrm{hr}$., due probably to two or three pin holes, were detected by applying air pressure of $15 \mathrm{lbs}$./in. ${ }^{2}$ and then immersing in water, but in other cases of leaks of this magnitude, due probably to a very large number of smaller holes, could not be detected in this manner.

If a tube leaks, through very fine capillaries or interstices (which are small in comparison with the mean free path of the gas molecules) then according to the kinetic theory, the volume of a gas passing through the tube by this means, should be directly proportional to the square root of the absolute temperature. In this case, calculations show that the mass (or volume reduced to standard conditions) of gas passing through the tube wall should be approximately 1.6 times as much at room temperature as at $500^{\circ} \mathrm{C}$. In the case of a few tubes, there is no doubt that these processes were the governing ones for temperatures up to $800^{\circ}$ or $1,000^{\circ} \mathrm{C}$., but at higher temperatures all the experimental data indicate an increase in the rate of flow of air with temperature.

In the two processes just discussed it is assumed that the dimensions of the holes are constant. Changes in the dimensions of the 
holes by thermal expansion of the material would normally be expected to cause relatively small changes in the rate of flow.

Since both of these processes would be expected to give a relationship between leakage and temperature very different from that observed, it is interesting to consider the third process suggested at the beginning of this discussion, the diffusion of dissolved gases through the solid. From what little we know of such processes, their rapidity appears to bear some such relationship to temperature as is needed to explain the observed phenomenon.

We might expect solution and diffusion to take place at about the same rate in different tubes of the same general composition and to find much more rapid diffusion through a thin walled tube than a thick walled one. This may be true only if the tubes have received approximately the same mechanical and thermal treatments during manufacture. If we compare tubes 7, 8, and 9 of manufacturer A, which so far as we know are made of essentially the same materials, and all of which show about the same relative relationship between temperature and the rate at which gas appeared in the tubes, we find that the $3.5-\mathrm{mm}$ tubes showed about six times the apparent permeability of the $1 \mathrm{~mm}$ tube instead of a third or a fourth of the permeability as might have been expected. There is no assurance, however, that the thin and thick walled tubes had received the same mechanical and thermal treatments. In fact, microscopic examination showed differences in the structure of the material in these two types of tubes and it is therefore possible that the large difference in the rates of apparent diffusion may be due to some differences associated with the body structures.

Similarly, the permeability of three nickel-chromium tubes of the same wall thickness from manufacturer $K$, all of which showed similar increases in apparent permeability with increasing temperature varied from 770 to $6,000 \times 10^{-6} \mathrm{~cm}^{3} / \mathrm{hr}$.-cm. ${ }^{2}$ at $1,000^{\circ} \mathrm{C}$. Such results with materials of similar, if not identical chemical composition, are possibly caused by differences in constitution dependent on variations in mechanical and thermal treatments.

It is, of course, possible that the gas collected in the case of the tubes which showed these very high temperature coefficients did not come through the tubes at all, but was originally adsorbed on the walls or in the pores of the material or came from the decomposition of some constituent of the complex solid. Time did not permit the verification of any one of these several possible hypotheses as to the origin and method of transmission of the gas collected.

Either the driving off of adsorved gases of the decomposition of dissolved carbides, oxides, sulphides, etc., might be expected to have some such relationship to temperature as was observed. The fact that repeated long evacuation at high temperatures did not, within the limit of measurement, decrease the rate at which gas was collected, may be taken as evidence indicative that the gas came from outside the tube.

If porcelain and silica tubes are free from holes they may be used as protection tubes for platinum couples in a reducing atmosphere for a considerable time without detrimental contamination of the couple. The reducing gas will reduce the silica at the outer surface of the tube leaving a coating of silicon which is of no consequence until the action has proceeded far enough into the tube to reach pores communicating with the interior. In the case of a very porous 
porcelain body glazed on the outside, the period of effectiveness of the protection may be comparatively short in an extremely reducing atmosphere.

\section{SUMMARY}

The results of the measurements of the rate of passage of air through 36 tubes of refractory porcelain, both glazed and unglazed, (11 different classes) 2 of fused silica, 1 of pyrex glass, 2 of alundum, and 15 of metal are given for various temperatures which the tubes would withstand without noticeable deformation. The tests indicate that the very refractory porcelain tubes (often referred to as sillimanite or mullite) are decidedly superior to the older porcelain tubes, both in refractoriness and gas tightness.

The results indicate that tubes of calorized wrought iron are more gas tight than those of other metals at the higher temperatures. Nickel-chromium tubes, in general, were more gas tight than those of other alloys.

The tests also showed that it was possible to maintain pressures of less than $0.001 \mathrm{~mm}$ of $\mathrm{Hg}$ in a refractory porcelain tube at $1,400^{\circ}$ C. by the use of an ordinary laboratory type mercury vapor pump.

Methods of testing are described and a very brief discussion given of the processes by which air may pass through the tube walls.

No attempt has been made to correlate the data reported in this paper with data obtained by other observers, since measurements have not been made under similar conditions. Most of the data reported have been on the passage of gases through glass, silica, and metals. No data have been found on the passage of air through solids or on the passages of gases through porcelain.

\section{BIBLIOGRAPHY}

A selected bibliography is given here for those interested in this subject:

(Richardson and Ditto, Diffusion of Neon through Hot Quartz, Phil. Mag., 22, p. 704; November, 1911.

Charpy and Bonnerot, Permeability of Iron to Hydrogen, Comptes Rendus, 154, p. 592 ; Feburary, 1912.

A. Holt, Diffusion of Hydrogen through Palladium, Roy. Soc. Proc., 91, p. 148; February, 1915.

E. C. Mayer, Leakage of Gases through Quartz Tubes, Phys. Rev., 6, p. 283; October, 1915.

Edwards and Pickering, Permeability of Rubber to Gases, B. S. Bull. 16, p. 327; 1920.

E. Cardoso, Diffusion of Hydrogen, Helium, and Neon Through Heated Glass, Accad. Lincei. Atti., 31, 1, p. 28; 1922.

Schmidt and Lucke, Diffusion of Hydrogen through Iron and Platinum, Zeits. f. Physik, 8, 3, p. 152; 1922.

Johnson and Burt, Passage of Hydrogen through Quartz Glass, J. Opt. Soc. Amr. 6, p. 734; 1922.

Deming and Hendricks, The Diffusion of Hydrogen through Metals, J., Am. Chem. Soc., 45, p. 2857; 1923.

V. Lombard, Permeability of Iron and Platinum to Hydrogen Gas, Compt. Rend., 184, p. $1557 ; 1927$.

V. Lombard, Permeability of Nickel to Hydrogen Gas. Effect of Thickness of Metal, Compt. Rend., 184, p. 1327; 1927.

Borelius and Lindblom, Diffusion of Hydrogen through Iron., Ann. d. Physik., 82, 4, p. 201; 1927.

G. Borelius, Solubility and Diffusion of Hydrogen in Metals, Ann. d. Physik. 83, 4, p. $121 ; 1927$.

W. E. Deming, Diffusion of Hydrogen through Iron, Phil. Mag., 5, p. 1081; 1928.

Washington, May 20, 1931. 